\title{
MEASURING THE SOLAR POTENTIAL OF A CITY AND ITS IMPLICATIONS ON ENERGY POLICY
}

\author{
Hugh Byrd ${ }^{1}$, Anna $\mathrm{Ho}^{1}$, Basil Sharp ${ }^{1}$, Nirmal-Kumar Nair ${ }^{1}$ \\ University of Auckland, New Zealand \\ h.byrd@auckland.ac.nz
}

\begin{abstract}
This research investigates the maximum potential energy that can be made available by efficiently installing PV systems on buildings throughout a city, from the central business district (CBD) out to low density suburbs. The purpose of this is to evaluate the contribution that electricity from PVs can make to reduce the electricity load of a city, supply the needs of a mixture of building types, reduce peak electricity demand and contribute towards the charging of electric vehicles (EVs).
\end{abstract}

A sample of the main urban building types have been taken and reassembled into a representative typical cross-section of a city. The application of PVs for all the building types is investigated and then the potential electricity distribution is evaluated for different urban densities and dispersion patterns. This research is concerned not only with how individual buildings may gain from distributed generation (DG) but, more importantly, how a city as a whole may benefit.

The results indicate that low dense suburbia is not only the most efficient collector of solar energy but that enough excess electricity can be generated to power daily transport needs of suburbia and also contribute to peak daytime electrical loads in the city centre. This challenges conventional thinking that suburbia is energy inefficient. While a compact city may be more efficient for the internal combustion engine vehicles, a dispersed city is more efficient when DG solar power is the main energy source and EVs are the means of transport.

\section{INTRODUCTION}

Cities utilise solar energy through passive means of heating and lighting buildings and active means by heating water. A further means, and one of significant growth (IEA, 2010), has been the use of photovoltaics (PVs) to produce electricity by distributed generation (DG). DG has all the advantages of renewable energy systems, such as reduced carbon emissions, offsetting dependence on the electricity grid and long-term energy security. However, it also has the potential advantages within a city of reducing peak electric demand, contributing to transport energy (electric vehicles) and reducing transmission inefficiencies, where grid electricity generation is remote from a city.

This research is concerned not only with how individual buildings may gain from DG but, more importantly, how a city as a whole may benefit. In many countries a subsidised feed-in tariff (FiT) has been introduced which results in the DG of electricity being fed into the grid which can be considered as a 'virtual store' of energy. In this 
study we have not taken account of an FiT for two main reasons. Firstly, there is no FiT in New Zealand and no indication that there ever will be, on the basis that it distorts the market. Secondly, FiTs in other countries will disappear over time leaving PV owners looking for the most effective way of using the electricity that was previously fed into the grid at a subsidised price. This study indicates a possible alternative use for DG energy.

This research investigates the maximum potential energy that can be made available by efficiently installing PV systems on buildings throughout a city, from the central business district (CBD) out to low density suburbs. The purpose of this is to evaluate the contribution that electricity from PVs can make to reduce the electricity load of a city, supply the needs of a mixture of building types, reduce peak electricity demand and contribute towards the charging of EVs. This will have implications not only on the electrical distribution system of a city but also on urban form. The study does not address how rapidly this may occur or the impact of these technologies as they gradually penetrate the market. Instead, it looks at the idea of a city maximising the use of these technologies. From this, the interim stages leading up to full implementation can be 'backcasted' (Holmberg, 2000).

As PVs and EVs become more cost-effective, the synergies of generator and storage system in these technologies will have an impact of not only reducing energy use by greater efficiency, but also reducing the impact of externalities caused by noise and air pollution. This research will show that the low density suburbs, with large roof areas and low daytime electricity demand, are capable of producing surplus electricity that, in the absence of an FiT, is most effectively used for charging EVs.

The results of this research completely reverse the argument for a 'compact city' based on transport energy use. While dense cities may be more efficient for petrol driven transport energy use (Newman \& Kenworthy, 1989), a dispersed city is more efficient when EVs, charged by PVs, are the main means of transport. The solar mapping and 'net-metering' mapping proposed in this paper provide a basis for energy policy in urban areas where the emerging technologies of EVs, PVs and smart meters replace the fossil fuel technologies of the present and past.

\section{WHY CONSIDER 'SOLAR POTENTIAL'}

The purpose of this paper is to quantify the full potential that DG by PVs may have on a city. To do this, a sample of the main building types of a city have been taken and reassembled into a representative cross-section of a city. The potential application of PVs for all the building types is investigated and then the electricity distribution is evaluated. This includes the use of electricity for the building itself or for charging EVs as well as feeding-in the electricity to the grid for sharing or peak load shaving (Electricity Commission, 2010).

While the analysis of the data can be used for many cities, the city of Auckland in New Zealand has been selected as the case study. The City has several characteristics that 
make it of particular interest for a study of solar energy potential. Annual solar radiation levels are equivalent to Barcelona and Los Angeles (IT Power, 2009). It is a city that has grown around a dependence on cars (Huang et al, 2010) and consequently has a dispersed urban form and a dependence on imported oil (Ho \& Byrd, 2011). Approximately half of New Zealand's energy consumption is imported oil of which about $80 \%$ is for domestic transport (MED, 2011) This makes the city very attractive for EVs to replace internal combustion engine vehicles (ICEVs).

It is also a city where the buildings, both residential and commercial, increasingly rely on air-conditioning with a consequent increase in the summertime peak electricity load (Byrd \& Segedin, 2010). The suburbs are largely made up of detached, single-storey houses that have large roof areas suitable for PV installations (Ho \& Byrd, 2011).

However, New Zealand does not have a subsidised feed-in tariff (FiT), as exists in many other countries (Grinlinton, 2010), and PV penetration into the market relies on commercial viability and competition for electricity price with the suppliers who obtain electricity from relatively large scale generators using hydro, geothermal, natural gas and coal (IT Power, 2009). About $70 \%$ of New Zealand's electricity supply is from renewable energy resources (MED, 2011). Although this has the advantages of low carbon production it also makes the electricity supply vulnerable to the vagaries of the weather. A dry year, such as 2012, has significant consequences on the price of electricity (Evans, 2012). Distributed generation of electricity by PVs offers another source of clean energy that can supplement, albeit in the daytime only, other sources of electricity and increase energy security.

New Zealand is also vulnerable to climate change. With over $65 \%$ of electricity generated by hydro (Electricity Authority, 2011), there are longer term issues to be considered such as the competition for water between electricity generation on one hand and irrigation of farm land on the other. Furthermore, the main hydro areas of New Zealand lie at the bottom end of the South Island while the main consumer, the City of Auckland, lies towards the top of the North Island, a distance of about 1,500 kilometres. It has been estimated that distribution losses between these generators and consumers can be in the order of 30\% (Birss, 2006). Distributed generation, at the point of use, overcomes these transmission losses.

\section{THE TYPICAL CROSS-SECTION OF THE CITY}

Taking Auckland as the case study, typical sections of the city were selected as representing common building types within the urban context. The representative areas were taken from established 'meshblocks' (Statistics New Zealand, 2012) within the city. Meshblocks are geographical areas which form the basis of census data. The analysis started from meshblocks in the CBD, typified by tall commercial buildings, hotels and apartments, and then moving out through the light industrial, low rise commercial and large retail towards suburbia. Suburbia consists of house types that range from densities of 125 dwelling/ ha near the City centre to about 14 dwelling/ha on 
the periphery of the city. These are illustrated in figure 1 . The total floor area of the sample size is about one-third of a million square meters of a range of different building types and uses.

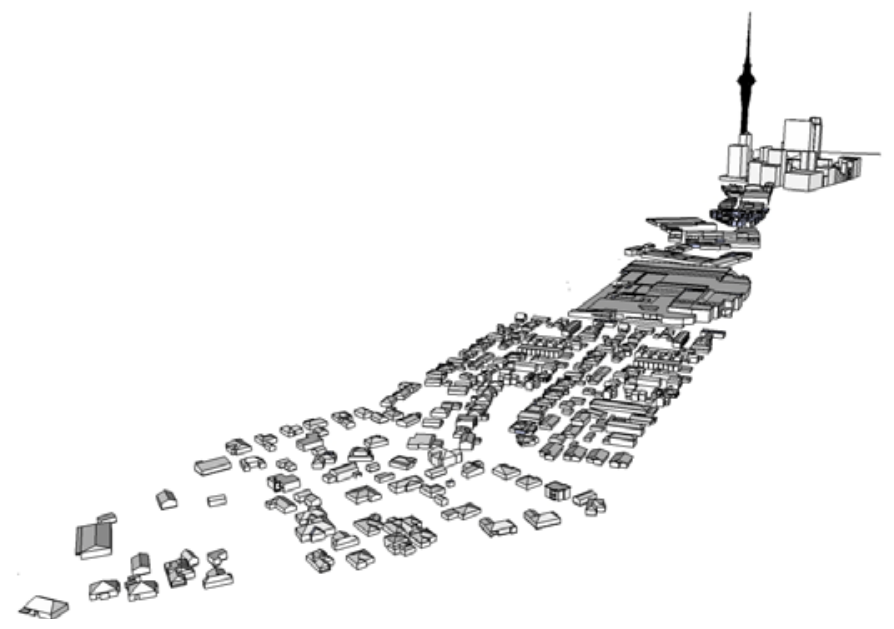

Fig. 1: The sample of buildings: a typical section through the city.

Different building types and uses from the CBD to the outer suburbs, $10 \mathrm{~km}$ away.

\section{ANALYSING PV ENERGY SUPPLY}

PV energy supply can be calculated by the product of the area of the PV array, the efficiency of the PV and inverter system and the efficiency due to the orientation and tilt of the array. For all the building types annual energy supply was calculated based on an overall PV system efficiency of $12 \%$.

In considering the potential locations for PVs on the representative buildings, it was assumed that only the most efficient orientation and tilts should be considered. For the purposes of this study, it was assumed that all arrays were static (non-tracking) and that they faced the most efficient direction for annual solar collection for the given location.

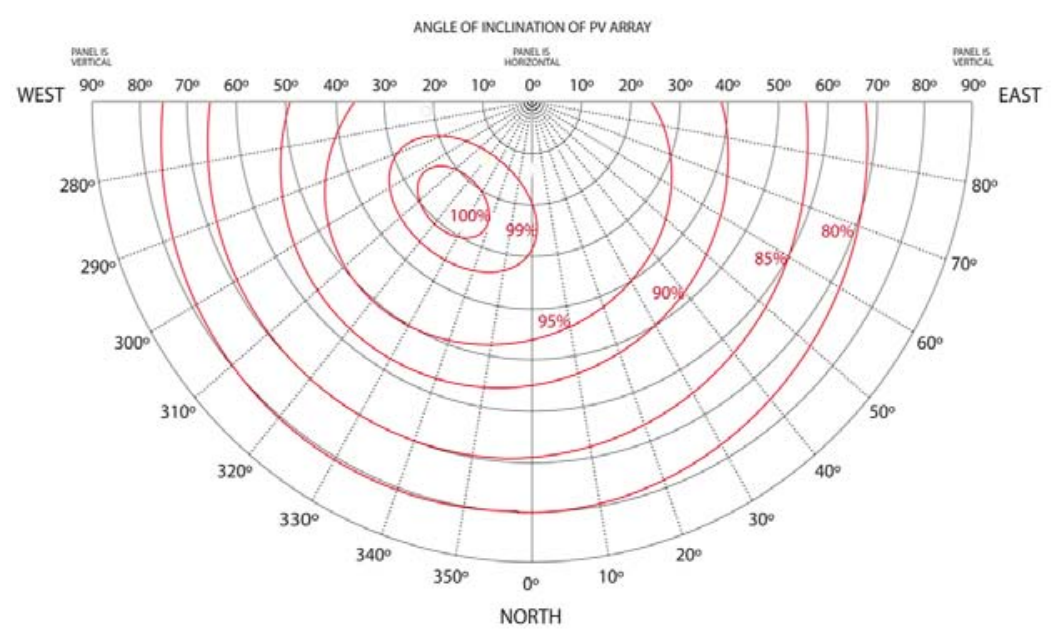

Fig. 2: Protractor for PV efficiency in Auckland, depending on orientation and tilt.

Figure 2 illustrates the efficiency of solar collection related to tilt and orientation of panel for Auckland (Wong \& Byrd, 2011). Only elements of buildings, (roofs or facades) 
with an efficiency range of $95 \%$ or greater were considered for the installation of PVs. This target is a balance between ensuring that the installation is economically viable while allowing considerable flexibility in orientation and tilt. As a rule of thumb, a PV system operating at $95 \%$ efficiency, due to its directional properties, allows tilts of anywhere between horizontal to 45 degrees and orientations of between northeast to west.

\section{TALL BUILDINGS}

This criterion of 95\% efficiency eliminates the use of PVs on vertical surfaces, which has significant implications for tall buildings. Figure 3 illustrates the annual average solar radiation (calculated using Ecotect software) on the sample of buildings taken in the City centre. The colour gradient indicates that the solar energy available of the vertical surfaces is less than half that on the roofs.

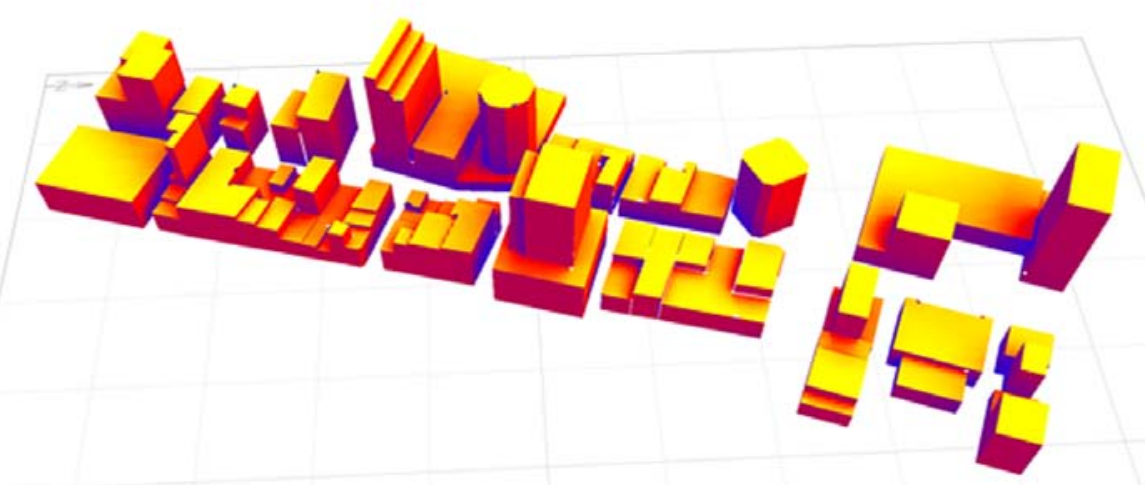

Fig. 3: Average annual solar radiation on sample of buildings in Auckland's CBD.

Roofs have typically twice the radiation as walls that are unshaded or obstructed.

For the purposes of this study, the use of PVs on vertical surfaces of tall buildings has been discounted for other reasons as well as efficiency. Firstly, PVs can reduce the amount of daylight (passive solar energy in the visible spectrum) entering tall buildings. The value of daylight for displacing electric lighting is far greater than the electricity provided by the PVs. Secondly, while PVs could be used as integral shading devices to reduce cooling load, the ability to implement this in Auckland is limited by the proximity of facades to plot boundaries (Byrd 2012). Floor area is built to the boundary in order to maximise rental that, in turn, has a higher value than the energy required for excessive cooling loads. Thirdly, without solar access rights in urban areas, there is no security of electricity production in the event of a new development overshadowing existing PV installations.

\section{RESIDENTIAL AND COMMERCIAL BUILDINGS}

On all residential buildings, including high rise developments, it was assumed that solar panels for hot water would take priority over PVs on roofs, since the thermal conversion in these panels is significantly more efficient and cost effective than PVs. PVs on flat roofs were assumed to be tilted to 10 degrees toward the optimum orientation so that 
their efficiency could be maintained by self-cleaning from the rain. Significant obstacles on roofs, such as plant rooms and safe working areas that are prevalent on apartments, were taken into account and the area of potential PVs reduced accordingly.

For low rise housing, the complexity of roof forms was taken into account by analysing not only the orientation and tilt but also the ability to install a rectilinear array based on a standard module size of $800 \times 1600 \mathrm{~mm}$. From the sample of houses (figure 1), and the use of the protractor (figure 2) it was possible to relate typical residential roof forms to their capacity for efficient PV installation and, hence, electricity production (figure 4).
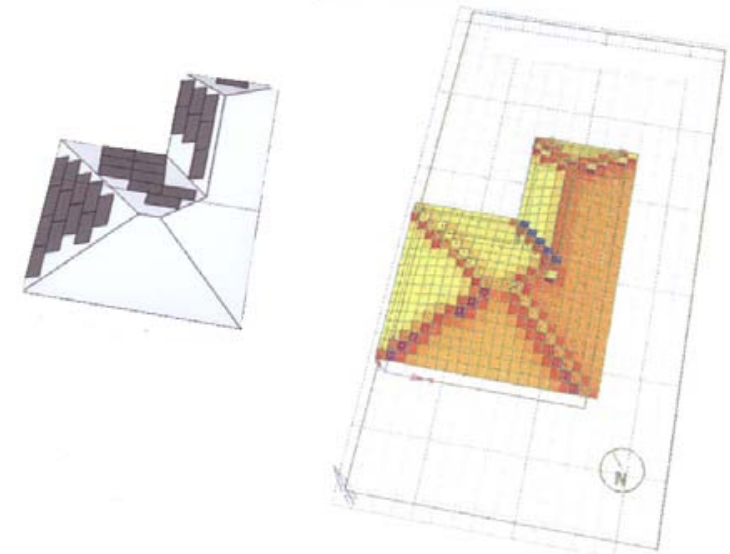

Fig. 4: Analysing the capacity of residential roofs for PVs taking account of orientation, tilt and PV module.

The commercial buildings away from the city centre were typically low rise with a large roof area to floor area ratio. Large span industrial sheds are frequently used for either light industry, office, retail or shopping centre. These roofs have significant potential for implementing PVs. However, the energy consumed by the different uses under the roofs varied considerably and impacted on whether the net energy from the PVs could be fed into the grid or not. This is discussed further below.

\section{ANALYSING THE ENERGY USE OF THE BUILDINGS}

In order to analyse the potential use of the PV energy supply, the electricity demand of all the building types was analysed both annually and on a daily basis. This assists in establishing how much PV electricity a building will consume itself and how much excess it may produce at certain times of the day for either storing or returning to the grid system.

The energy used by the buildings was based on energy benchmarks of buildings types taken from several sources. There are various sources of energy use benchmarks for different buildings in New Zealand including the Property Council of New Zealand (2000), Isaacs (1993), EECA (2012), and BRANZ (2010). The sample of buildings (figure 1) was analysed according to the energy benchmark categories measured in $\mathrm{kWh} / \mathrm{m}^{2} /$ year. This was then compared with the potential electricity generated by PVs on the same buildings, also measured in $\mathrm{kWh} / \mathrm{m}^{2} /$ year. This is illustrated in figure 5 which indicates the relative energy generation and consumption in the bar charts under 
the various typical building types. When energy generated (bar chart below the origin line) is greater than consumption (bars above the origin), the building type has a net surplus of energy. The diagram illustrates that suburbia has a net surplus while the CBD has a significant deficit. It is important to note that the energy consumption indicated is for daytime only as this is the time when PVs can directly contribute.

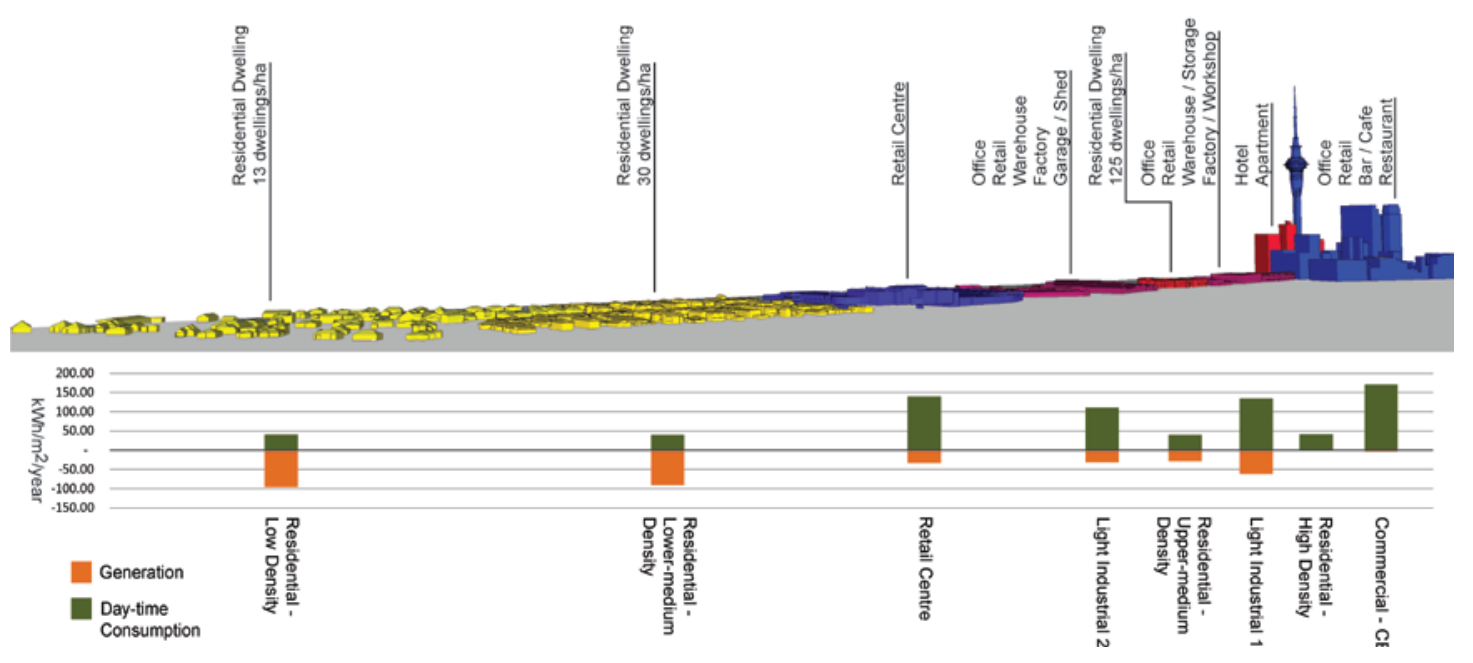

Fig. 5: Cross-section of sample showing the relative energy generation by PVs and consumption of buildings during the daytime (net-metering).

\section{MATCHING ENERGY GENERATION BY PVS TO ENERGY CONSUMPTION}

Figure 6 illustrates the relative energy consumption and generation by the different building types. In this figure, both the 'total' (day and night) as well as 'day-time' only energy consumption is indicated.

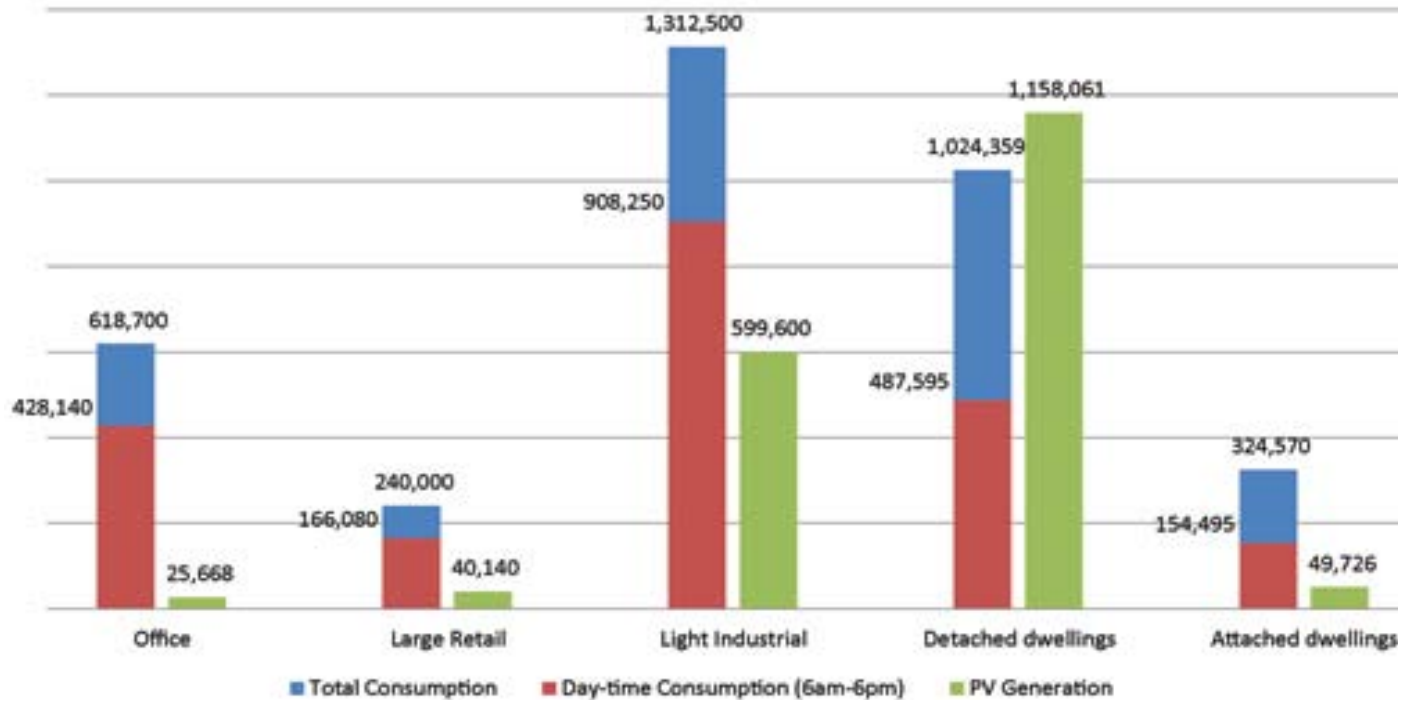

Fig. 6: Annual energy consumption of building types (day-time \& total) compared with PV energy generation $(\mathrm{kWh})$.

Only in the case of 'detached dwellings' is the PV generation potential greater than the total energy use. It should be noted that the total energy consumption for dwellings assumes that 
solar hot water heating has been installed which reduces the total household energy consumption by around $20 \%$. Without solar hot water heating, PV energy would not exceed total household energy.

The reason that PV energy on 'attached dwellings' is so low is that this category contains multistorey house types with low roof: floor area ratios. In the extreme case of apartments, the roofs can only just accommodate solar hot water panels with no space left for PVs.

The 'offices' category is dominated by tall buildings which have little roof space available after roof mounted plant rooms and safe working areas are excluded. 'Light industrial' has both a large PV potential as well as large daytime energy consumption. However, it illustrates a significant potential for PVs on these building types to reduce their daytime energy consumption and the possibility of exporting surplus electricity at weekends.

The overall implication from these results is that 'detached dwellings' can contribute surplus energy to the city during the daytime. In Auckland, 'detached dwellings' have typical densities of between 14 to 30 households per hectare: suburbia.

\section{EXTRAPOLATING THE RESULTS OF THE SAMPLE TO THE WHOLE CITY}

The results from the sample 'section' through the City can be translated across the whole city by observing the different building types and their prevalence within different areas. Maps can be drawn up that show both the PV generation potential (without taking account of consumption) and the potential after a building's energy consumption is taken into account (net metering).
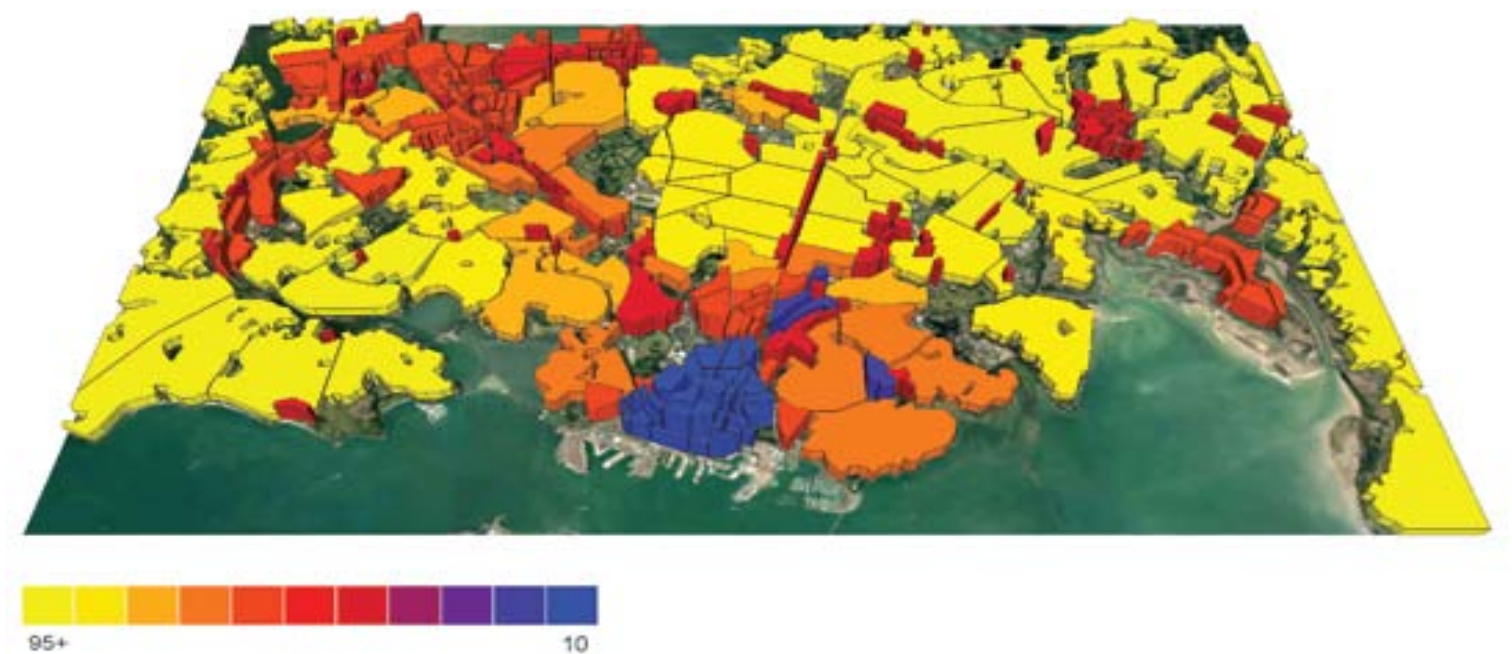

Fig. 7: Solar energy generation potential $\left(\mathrm{kWh} / \mathrm{m}^{2}\right.$ floor area/year).

Figure 7 indicates the PV solar generation potential by building type across the City. As expected, the large roof area: floor area ratios of dwellings in suburbia have the greatest potential, supplying about ten times the amount of energy $\left(\mathrm{kWh} / \mathrm{m}^{2}\right.$ floor area/year) than the typical CBD buildings. This makes them a valuable source of energy in the future that has been well argued by Kellett (2011) in his article 'More than a roof over our head'. 
Figure 8 takes account of the daytime energy consumed by buildings under the PV systems accounted for in figure 7. For all intents and purposes, the figure is a 'netmetering' map and indicates which parts of the City contribute (net surplus) and which parts are net consumers. Again, low density suburbia holds the key to contributing to the City, while the high density areas are the major consumers.

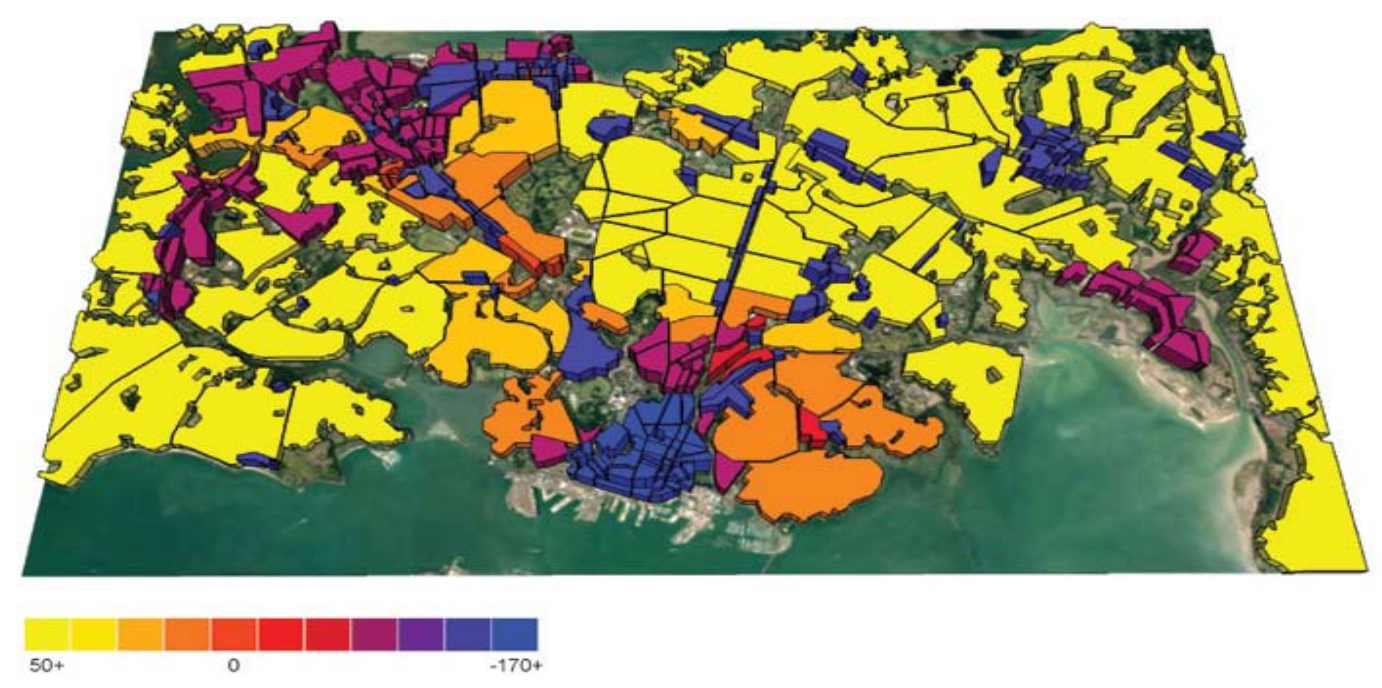

Fig. 8: Net-metering potential due to solar energy ( $\mathrm{kWh} / \mathrm{m}^{2}$ floor area/year). Orange to yellow colour indicates a net contribution to the City. Red to blue; a net deficit.

\section{OPTIMISING THE ENERGY SURPLUS FROM THE SUBURBS}

The surplus energy produced during the daytime occurs because of the relatively low electricity demand from households and large roof areas. Figure 9 illustrates the demand of a typical household in Auckland and the energy supplied by a 3.5kWp PV array. The graph illustrates the energy generated as well as household electricity use for both summer and winter. There are various choices that a householder can make if they have

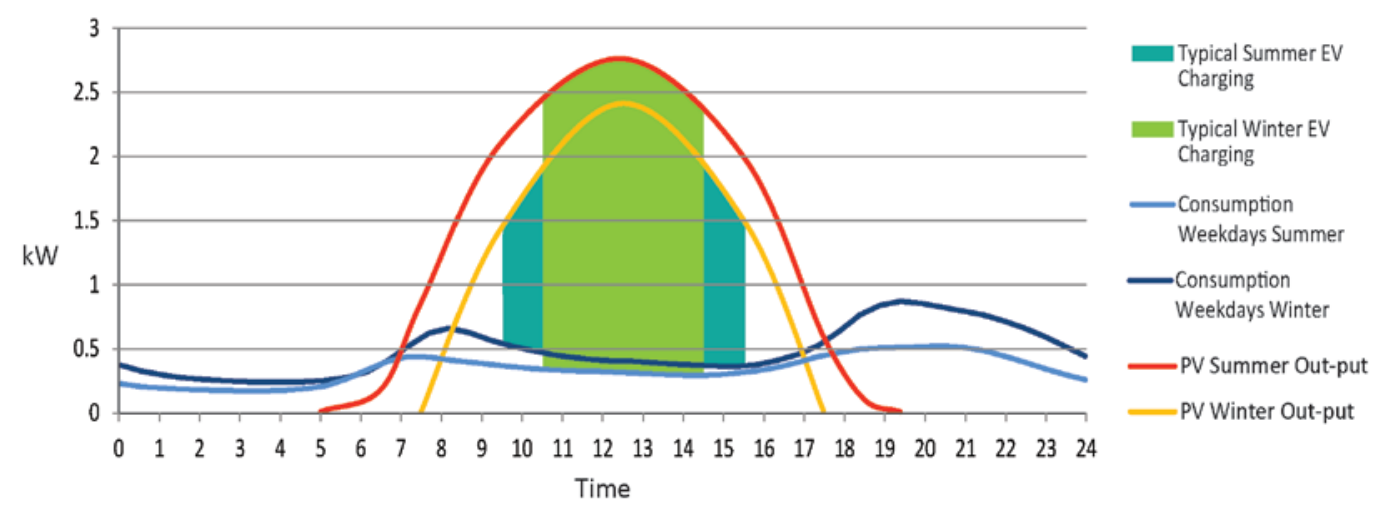

Fig. 9: Typical household daily energy consumption and generation (3.5 kWp array). Shaded area indicates possible EV charging scenarios. 
1. All the generated electricity can be fed into the grid. This may be appropriate when there is a subsidised FiT.

2. The household electricity demand could be first satisfied before feeding surplus to the grid. Lifestyle patterns may be changed to optimise the use of this generated electricity by altering the operating times of appliances.

3. The surplus could be stored in batteries, whether fixed or contained in an electric vehicle. This could then be used for travel or feeding to the grid at an optimum time.

For the purposes of this research, where no feed-in tariff is considered, a combination of options 2 and 3 have been selected for further analysis. The choice between whether to charge an electric vehicle or to use the electricity for household appliances will depend on several factors including the travel patterns (distance and time of day) and electricity tariffs over a 24 hour period.

\section{ELECTRIC VEHICLE ENERGY CONSUMPTION IN AUCKLAND}

The amount of electricity required to charge an EV in Auckland's suburbs is described in Ho \& Byrd (2011) and is based on detailed information on travel patterns included in a report by Abley, et al, (2008); the 'National Travel Profile'. This research was commissioned by NZ Transport Agency and is an evaluation of the extensive continuous survey information collected by the New Zealand Household Travel Survey from 2003-2006. For the research in this paper, the travel distance is based on the furthest suburb from the City (figure 1) and amounts to $40 \mathrm{~km}$ per day. This is converted to electrical energy used by the vehicle based on the assumptions in Dukes et al (2009) paper; 'The Feasibility of Long Range Battery Electric Cars in New Zealand'.

There are two assumptions built into figure 9. The first is that the pattern of driving EVs will be the same as ICEVs are at present. This is likely to be a significant overestimate since driving patterns and habits are likely to change due to 'range anxiety' and also the feedback from EV-driver interfaces that warn of excessive consumption.

The second assumption is that EVs will be available to be charged in the middle of the day. The argument against such an assumption is the tendency to project existing life patterns on to the future and assume that cars are only used for commuting. This pattern of travel may well continue for some people, but for others, the future has other opportunities of travel. Commuting to work is only a relatively small part of vehicle travel in Auckland. According to The National Travel Profile (Abley et al, 2008), 'work to main job' travel is only $22 \%$ of a 'vehicle driver's mean travel distance in major urban areas'. The remaining $78 \%$ is for recreation, shopping, social visits, education and other activities that frequently happen outside peak PV generating times, which mean cars can be at home during the day if there are other opportunities for commuting to work.

This could be accommodated by the likely increase in the use of public transport or carpooling, both of which allow a vehicle to remain charging at home. Indeed, the 
increased value of charging from home during the daytime may well encourage the use of public transport for commuting.

The options and choices of fully or partially charging an EV by PVs or by the grid at different times of the day or night is an area of study that is required once EVs begin to have market penetration.

\section{IMPACT OF PVS AND EVS ON URBAN POLICY}

A study by IT Power (2009) for the New Zealand Ministry of Economic Development, forecast that PV generated electricity will fall in price, while grid based electricity will rise. 'Grid parity' was predicted to arrive in the early 2020s and thereafter PV generated electricity would be more economical. This is about the same time that the New Zealand Electricity Commission (Smith 2009) predicted that EVs would exponentially penetrate the market. With PVs as a means of generating electricity cheaper than the grid and no incentive to feed it into the grid, the logical choice is to use the electricity for both household use and for transport. The future of Auckland's transport, as with many other cities, will be linked to the emerging technologies of PVs, EVs, the smart meter and the synergies of these technologies.

While conventional theory on urban form and transport energy suggests that an intensive urban form may be more energy efficient (Newman \& Kenworthy 1989), in terms of transport energy use for ICEVs, what will be the optimum urban form for a city using smart technologies?

To compare the energy consumed by EVs with the energy supplied by PVs and the relationship of this with urban density, the three factors involved; travel energy consumption; solar energy generation; and urban density are juxtaposed to illustrate the impact they have on each other.

Figure 10 illustrates a comparison of the energy used for travel, by both EVs and ICEVs, from the different residential areas with different densities and distance from the City. This graph simply endorses the compact city argument, although EVs use significantly less energy than ICEVs in urban areas by a factor of about four.

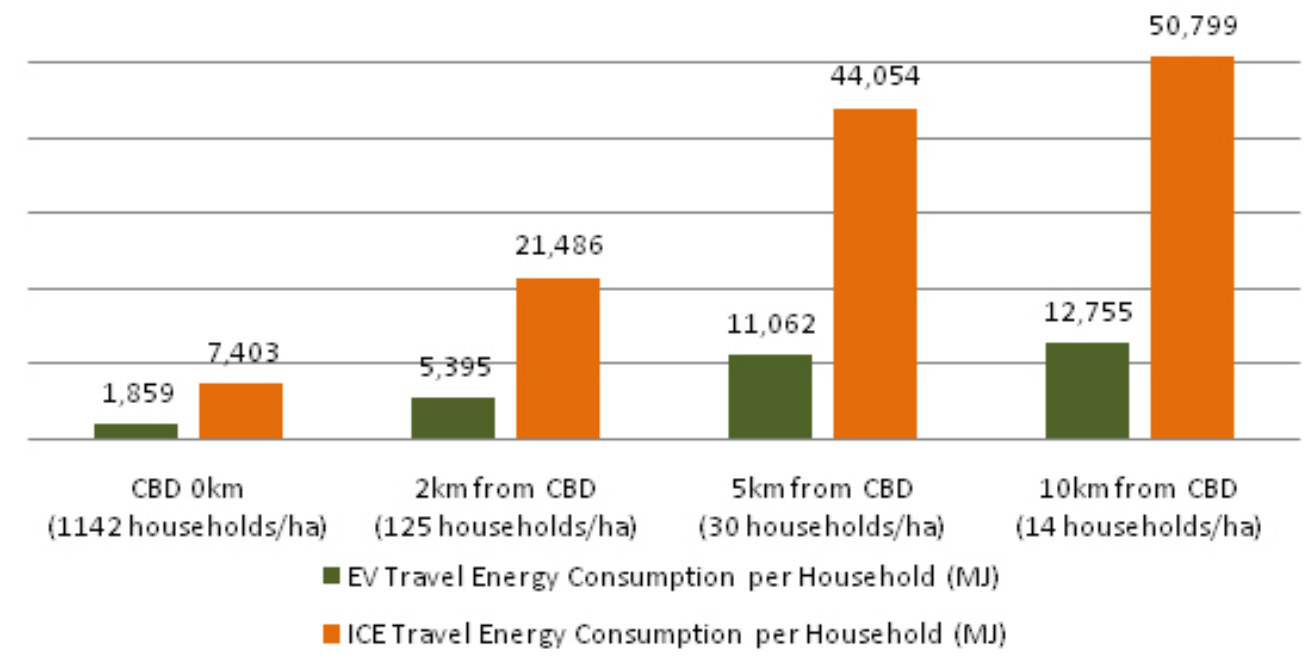

Fig. 10: Travel energy consumption comparison (MJ/household/year) 
Figure 11 illustrates the full potential of PV energy in the same sample. It should be noted that, for all residential sites, this study assumed that solar hot water heating would take preference to PVs and $4 \mathrm{~m}^{2}$ of efficient roof area per household was dedicated to solar hot water panels ( $3 \mathrm{~m}^{2}$ per household for apartments due to limited roof area). For high-rise residential buildings with low roof: floor area ratios, this resulted in no space being available for PVs. Assuming all the residential sites in the sample (figure 1) utilize their full solar potential, the energy generated could be sufficient to provide all their daily EV travel energy consumption.

Deducting the energy required to charge EVs (figure 10) from the energy obtained from PVs (figure 11), the net energy surplus or deficit can be compared with residential net density.

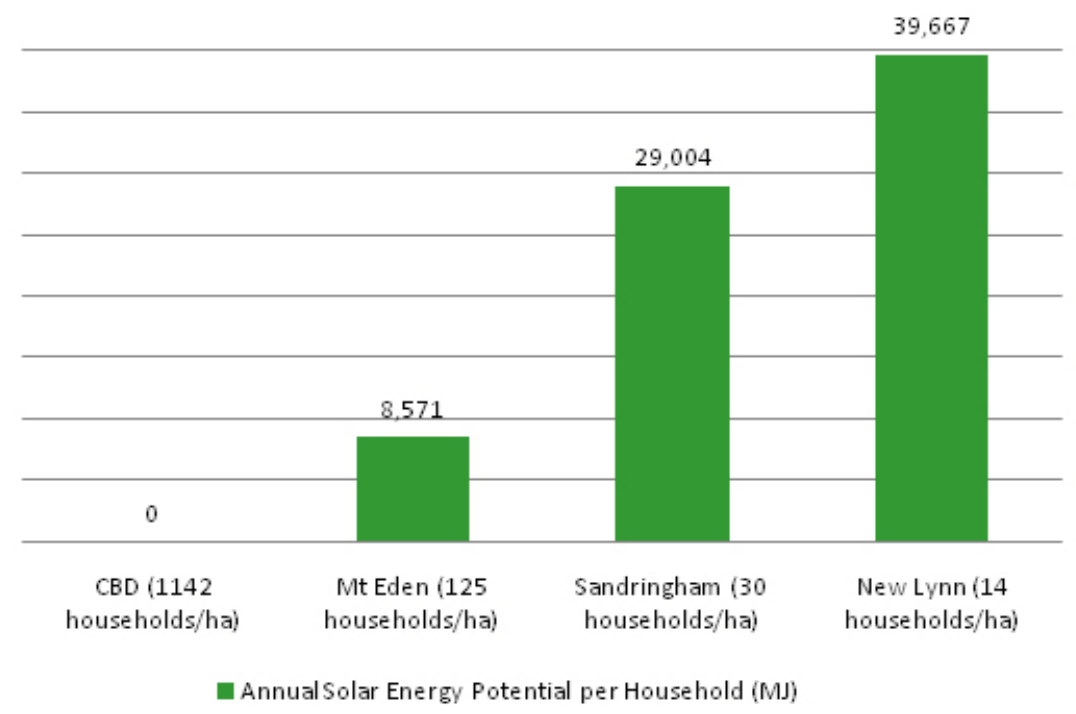

Fig. 11: Annual solar energy potential (MJ/year)

Figure 12 illustrates the relationship between energy and density for the different selected sites. The energy is measured in $\mathrm{MJ}$ of petrol equivalent against person per hectare so that it can be directly compared with the graph by Newman and Kenworthy (1989). The central curve illustrates Newman and Kenworthy's results for different cities (inter-cities). The upper curve is the ICEV consumption in this case study of Auckland (intra-city). The energy/density curve in Auckland follows a similar curve to that of Newman and Kenworthy.

However, when EVs powered by PV are included, adequate energy for transport and also a surplus is available for the three lower density sites. The curve in negative values indicates the surplus energy for the sites in accordance to their density level. Interestingly, this curve resembles a mirror image of the graph by Newman and Kenworthy, which suggests a reversal of the conventional theory on the relationship between density and travel energy consumption where, in the case of EV powered by PV generation, an inverse relationship can occur between travel energy consumption and density. 


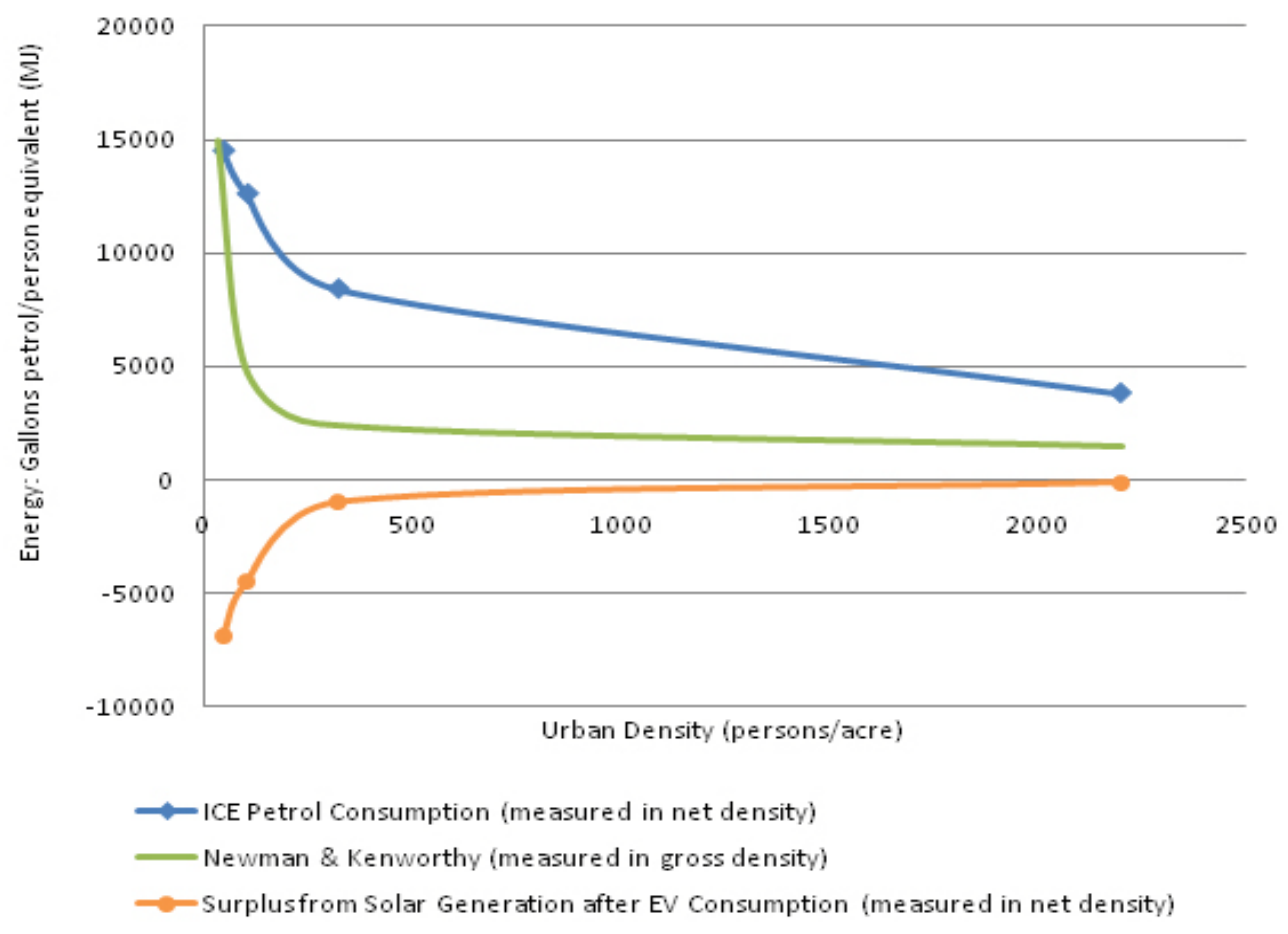

Fig. 12: The relationship between travel energy and residential density in Auckland. PVs provide enough energy to supply all household travel energy in suburbia and provide a surplus (negative figures).

\section{CONCLUSIONS}

A method of measuring and mapping the solar energy potential of a city has been described. This has been applied to the example of Auckland, New Zealand, and the full solar potential has been studied on the basis that any interim development in market penetration of PVs can be 'backcasted'.

The mapping indicates that lower density housing in suburbia has the greatest capacity for collecting solar energy and also the greatest surplus after its own energy uses have been taken into account (net-metering). The study has assumed that there is no subsidised feed-in tariff since this does not exist in New Zealand and is likely to be phased out internationally.

Without an FiT, surplus electricity generated by PVs has significant potential to charge EVs and, in New Zealand, the predicted future economic viability of PVs coincides with that of EVs. If PVs were to be used to charge EVs, as well as offset daytime household electricity use, there would still be a surplus of electricity even assuming current travel patterns persist.

This will have implications on the policy of urban form. Conventional theory on urban form and transport energy suggests that an intensive urban form may be more energy efficient, in terms of transport energy use, for vehicles using fossil fuels with internal combustion engines. However, in the foreseeable future, distributed generation by PVs could become commonplace and suburbia will have a renewed role as a collector of energy. Through the implementation of smart technologies, suburbia could transform to an energy contributor not only for its own transport needs but also to the city as a whole. 


\section{REFERENCES}

Birss, N. (2006) Power to Burn. New Zealand Investor, issue 143, August. Pp6-9

BRANZ (2010) Study Report: Energy Use in New Zealand Households: Final Report on the Household Energy End-use Project (HEEP). Table 4, pg14. http://www.branz.co.nz/cms_show_download.php?id=a9f5f2812c5d7d3d53fdaba15f2c $\underline{14 d 591749353}$

Byrd, H. (2012) Post Occupancy Evaluation of Green Buildings: The Measured Impact of Over-Glazing. Architectural Science Review. DOI:10.1080/00038628.2012.688017

Byrd, H. \& Segedin, E. (2010) New Directions for Research due to Climate Change in New Zealand. Paper for the 2010 Australasian Housing Researchers' Conference, 18 November, Auckland.

Dukes, M., Andrews, D., and Anderson, T., (2009) 'The Feasibility of Long Range Battery Electric Cars in New Zealand', ENERGY POLICY, Volume 37, Issue 9, September 2009

EECA (2012) New Guidelines to Help Bring Electric Vehicles to the Market. http://www.energywise.govt.nz/node/23112. Accessed March 2012

Electricity Commission (2010) Statement of Opportunities. www.electricitycommission.govt.nz

Electricity Authority, (2011) Electricity in New Zealand. http://www.ea.govt.nz/aboutus/documents-publications/electricity-nz/

Evans, G. (2012) Meridian Flags Winter Hydro Risk. Energy News, 16 Feb 2012. http://www.energynews.co.nz/news/hydro-lake-levels/8376/meridian-flags-winterhydro-risk-may-slow-retail-recruiting

Grinlinton, D. (2010) “The Role of Feed-In Tariffs in Supporting the Expansion of Solar Energy Production”, 41(3) University of Toledo Law Review 943-973.

Holmberg, J. \& Robèrt, K.H. 2000. Backcasting from non-overlapping sustainability principles: a framework for strategic planning. International Journal of Sustainable Development and World Ecology, 74, 291-308.

Ho, A \& Byrd, H. (2011) The impact of electric vehicles on the environmental issues of urban density in NZ. Proceedings of the 45th ANZAScA Conference, Sydney.

Huang N, Vale B \& Vale R (2010) Car or Public Transport? Some Lessons from Policy-making for Auckland's Transport. International Journal of Arts and Sciences. 3(13): 1 - 19 (2010)

IEA. (2010). Technology Roadmap: Solar Photovoltaic Energy. Paris: IEA. Retrieved from: http://www.iea.org/papers/2010/pv_roadmap.pdf

Isaacs, N. (1993) Thermal Efficiency in N.Z. Buildings. Centre for Building Performance Research, Victoria University of Wellington. 
IT Power Australia \& Southern Perspective. (2009). Assessment of the Future Costs and Performance of Solar Photovoltaic Technologies in New Zealand. Wellington: Ministry of Economic Development. Retrieved from: http://www.med.govt.nz/sectorsindustries/energy/pdf-docs-library/energy-data-and-modelling/technical-papers/pv-innew-zealand.pdf

Kellett J (2011) More Than A Roof Over Our Head: Can Planning Safeguard Rooftop Resources? Urban Policy \& Research, Vol. 29, No 1, 23-36

MED (2011) NZ Energy Strategy 2011-2012. p6 www.med.govt.nz/energy-strategy

Newman, P. \& Kenworthy, J. (1989). Gasoline Consumption and Cities - A Comparison of UK Cities with a Global Survey. Journal of the American Planning Association, 55(1), 24-37.

Property Council of New Zealand (2000) Energy Consumption Benchmarks: an analysis of the energy expenses incurred by New Zealand CBD Office buildings. Property Council of New Zealand Incorporated.

Smith (2009) "Electric Vehicles and generation development". NZ Electricity Commission. Conference on :The Impact of Electric Vehicles on the NZ Electricity System.

http://www.electricitycommission.govt.nz/pdfs/opdev/modelling/GPAs/presentations29Feb08/electricvehicles.pdf. Accessed July 2010

Statistics New Zealand (2006), Mapping Trends In The Auckland Region - Mapping Communting, http://www.stats.govt.nz/browse_for_stats/people_and_communities/geographicareas/mapping-trends-in-the-auckland-region/commuting.aspx Viewed 12/05/2011

Statistic New Zealand (2012) Geographic definitions. http://www.stats.govt.nz/Census/about-2006-census/2006-census-definitionsquestionnaires/definitions/geographic.aspx

Steemers, K. (2003) Energy and the city: density, buildings and transport . Energy and Buildings 35 (2003) 3-14

Wong, Z. and Byrd, H. (2011) Solar Potential of Schools. BRANZ Build, 120, 90-91. 